\title{
TEMPO-oxidized cellulose nanofibre (TOCN) films and composites with PVOH as sensitive dielectrics for microwave humidity sensing
}

\section{Introduction}

The development of highly competitive humidity sensing systems to address the ever-increasing needs in commercial, industrial and health applications is undergoing exponential growth [1, 2]. Various technologies to implement competitive humidity (RH) sensing mechanisms have been studied. $\mathrm{RF} /$ microwave technologies were recently considered for the design of wireless, passive and robust humidity sensing systems [3-5]. The research that aims to improve the competitiveness of microwave humidity sensing systems through high sensitivity, high selectivity, fast response and low hysteresis is currently conducted at the junction between microwave technologies and sensing materials [6, 7].

From the microwave technology viewpoint, radio frequency identification (RFID) and radar technologies have been widely investigated to fulfill remote assessment of humidity. Sensing methods included resonance shift when involving humidity-sensitive dielectrics, and RF power variation when involving humidity-sensitive conductors [8-10]. However, sensors designed with the above-mentioned technologies present some difficult challenges. Indeed, some of these challenges include the fact that sensitive schemes are limited, that microwave parameters worsen as humidity increases and that high Q-factor circuits are required to reach high performances. Transmission line technologies represent an interesting option to overcome these limitations. They provide flexibility to fulfill humidity sensing with a wide range of microwave structures and low Q-factor circuits [11]. In that respect, substrate integrating waveguide technology (SIW) and coplanar waveguide technology (CPW) have been broadly investigated.

SIW-based slotted devices are unique as they are able to sense humidity variations without sensing material. Moisture passes through the perforated dielectric substrate and modifies its effective dielectric constant. According to the theory of perturbations, the resonance then shifts by a value related to the humidity level $[12,13]$. SIW structures can be miniaturized through half mode (HMSIW), quote-mode (QMSIW) and ridged quarter-mode (RQMSIW) techniques while maintaining high results for humidity sensing $[14,15]$. Nevertheless, higher sensitivity with SIW-based devices is reached by the integration of sensitive materials. From this perspective, some humidity-sensitive materials have been studied. Graphene oxide (GO), for example, was integrated in a half-mode SIW resonator to increase the sensitivity from $312 \mathrm{kHz} / \% \mathrm{RH}$ to $772 \mathrm{kHz} / \% \mathrm{RH}$ in a $11.3-84.3 \% \mathrm{RH}$ range [16]. Likewise, it has been shown that the sensitivity of a SIW resonator can increase 40 times after integration of black phosphorus [4].

Aside from SIW, CPW demonstrated high sensitivity for humidity detection. Indeed, CPW-based devices are highly sensitive to dielectric surroundings, whether in the form of sheets, films or gels. CPW exhibits a planar outline that lowers fabrication steps compared to SIW, and offers a very high design flexibility by combination with slots [17]. Various hydrophilic/hydrophobic dielectrics derived from the literature can be integrated to CPW-based devices. On the one hand, this includes non-biodegradable materials such as organic/inorganic materials, organic polymers and ceramics that were intensively investigated through resistance or impedance sensors [18]. Sheets of various humidity-sensitive organic polymers such as Kapton and PVOH were investigated. These sheets were stacked on the top of the CPW-based device to integrate humidity-sensing capability. PVOH appears as considerably more sensitive than Kapton [19]. On the other hand, environmentally friendly materials have recently gained great interest, as environmental preservation has become a major concern worldwide. In this way, lignocellulosic biomass 
and cellulose, standing out for their biodegradability, widespread affordability and renewability were found to be very appealing [20].

Many approaches to achieve humidity sensing using cellulose as sensitive material have been studied in different technologies. Cellulose derivatives formed by grafting esters or other humidity-sensitive compounds such as acetyl butyrate have been studied [21]. Cellulose was used as a host-matrix enclosing sensitive conductive polymers such as polypyrrole, whose viscosity or grain size prevents direct integration within electrical devices [22]. Cellulose compounds like carboxymethyl cellulose (CMC) were also considered to merge their sensing mechanisms to sensitive organic conductive polymers like polyaniline (PANI) [23]. Moreover, environmentally-friendly oxidized cellulose for humidity sensing in microwave frequencies was investigated [24]. The 4-acetamido-2,2,6,6-tetramethyl-piperidin-1-oxyl (TEMPO) oxidation process swapped the primary hydroxide group of cellulose nanofibres with a carboxyl group, thereby improving their affinity to humidity [25]. TEMPO oxidized cellulose nanofibres (hereafter called TOCN) were prepared in sheets of a thickness of approximately $35 \mu \mathrm{m}$, making them suitable materials to achieve humidity sensing through CPW transmission line technology. It was shown that the higher the amount of TOCN there is, the higher the sensitivity. However, the amount of TOCN was capped at $0.5 \%$ wt to prevent the sheet deformation and, therefore, a decay of the sensing performance. Thus, the significant potential of TOCN in the design of highly sensitive humidity sensing systems remains largely under-exploited.

This paper investigates TOCN-based films as sensitive dielectrics for humidity sensing in RF/microwave frequencies. These films are formed by drying TOCN-based gels whose viscosity can be easily tailored to integrate humidity sensing capabilities to electrical structures with slots and cavities, as achievable with SIW or CPW technologies. Moreover, as opposed to their sheet counterparts, such films enclose higher amounts of TOCN, then resulting in better sensitivity. TOCN is first studied as a sensitive material in the form of $15 \mu \mathrm{m}$ thick films. The dielectric characterization of TOCN films as a function of humidity is performed. To investigate microwave humidity sensing performances, a slotted CPW-based resonator in the grounded CPW variable (CPWG) is designed, prototyped and tested. Resonators were chosen as they represent basic circuits from which numerous microwave architectures are designed. An original sensing scheme with reflected and transmitted electromagnetic (EM) signals across the CPWG-based structure is proposed, analyzed and validated experimentally. Moreover, TOCN is also studied as a host matrix incorporating PVOH to form TOCN/PVOH composite humidity-sensitive gels. Sensing performances are compared between TOCN films and TOCN/PVOH films, as well as TOCN films and TOCN sheets.

\section{Humidity Sensing Principle}

As illustrated in Fig. 1-a, CPWG ensures EM signal propagation through a 3D outline where signal and ground tracks separated by a small gap are coplanar on the upper side, and a ground plane entirely covers the lower side. The upper and the lower ground planes are connected to each other. This technology limits field dispersion, lowers microwave loss and allows the implementation of various microwave applications through a simple insertion of slots [17]. The CPWG microwave device studied in this paper is derived 
from [18] and its geometry is illustrated in Fig. 1-b. The slots delineate a rectangle within the central track on the upper side. Each slot influences the capacitive coupling between the CPWG line and the rectangle. To model and to analyze its microwave properties, an electrical model associating structural parameters of the CPWG-based circuit to the appropriate electrical components was derived from [26], as shown in Fig. 2.

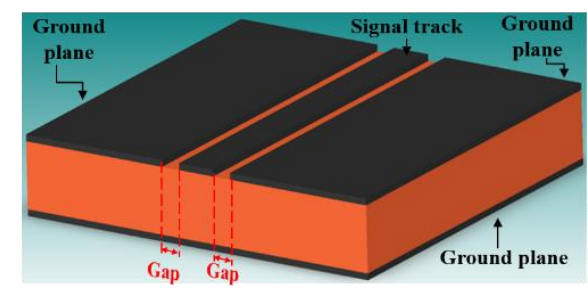

(a)

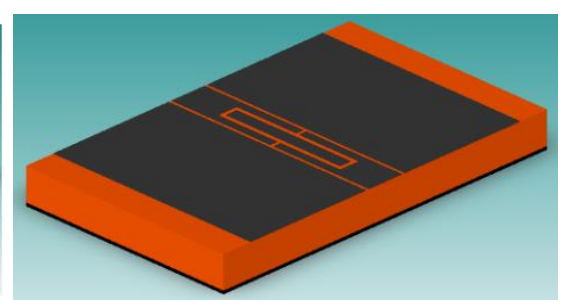

(b)

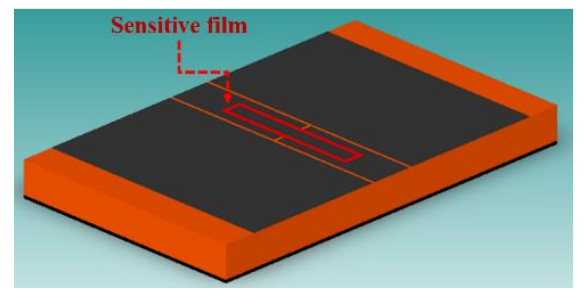

(c)

Fig. 1: CPWG transmission line technology circuits (a) CPWG line with parameters, (b) CPWG structure before functionalization and (c) CPWG structure with dielectric sensitive materials in red were dropped.
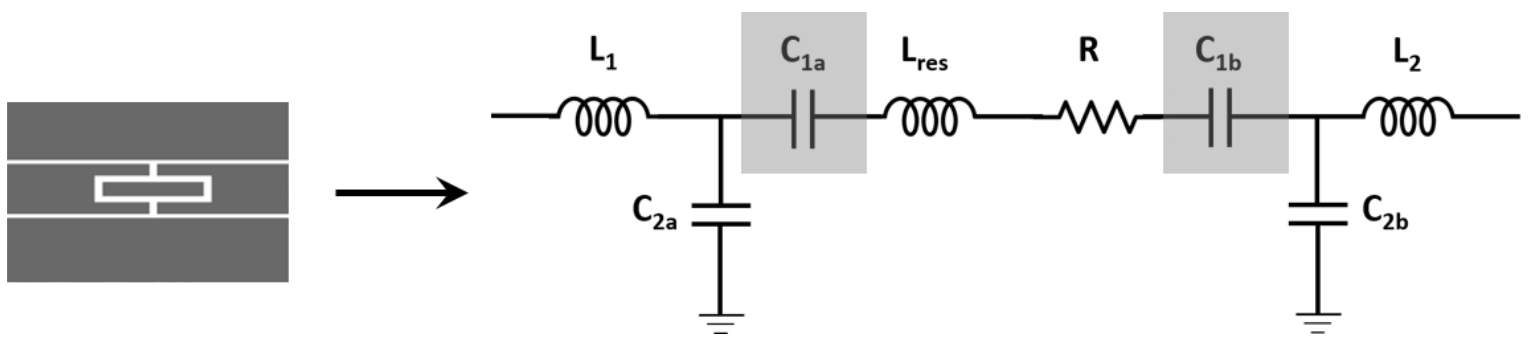

Fig. 2: Modelling of the CPWG device inspired from [26] and validated.

The CPWG line portions are represented by the $L_{1,2}$ inductors. $L_{r e s}$ and $R$ represent inductive and resistive interactions with the central rectangle respectively. The fringing effects and capacitance associated to the substrate are modelled by the capacity $C_{2 a, b}$. The capacitive coupling between the CPWG line and the rectangle is modelled by the capacity $C_{1 a, b}$, whose capacitance $\left(X_{1}\right)$ is given by equation (1), where $\omega$ is the pulsation and $Z_{0}$ is the characteristic impedance of the CPWG line [17]:

$$
X_{1}=\frac{1}{\omega \cdot C_{1 a, b} \cdot Z_{0}}
$$

The capacitance $X_{1}$ depends on the frequency through $\omega$, on the CPWG line dimensions through $Z_{0}$, and on the dielectric properties of the slot filler through $C_{1 a, b}$. Initially, when there is no filler as presented in Fig. 1-b, the microwave behaviour only depends on the dielectric properties of the air. The circuit has no sensing ability. The presence of the sensitive dielectric material within the slots separating the CPWG line and the central rectangle as shown in Fig. 1-c induces an increase of $C_{1 a, b}$ from the dielectric constant of the filler. Thereafter, any change on the dielectric properties of the filler is translated to a change of $C_{1 a, b}$ and therefore to a change of $X_{1}$ according to (1). The close relationship between the $C_{1 a, b}$ value and the dielectric properties of the filler explains why the nature of the dielectric filler defines the sensing 
application to be realized. Here, thanks to their hydrophilic nature, the TOCN-based materials induce a change of $C_{1 a, b}$ and $X_{1}$ as a function of humidity. As a result, the intensity of the capacitive coupling between the CPWG line and the central rectangle is influenced by the humidity value. The propagation of EM signals travelling through the CPWG-based circuit either in reflection or in transmission will be affected by humidity, both in magnitude and phase [27]. Following this principle, microwave parameters such as resonant frequency and transmission phase can be used as measurement variables associated to reflected and transmitted signals respectively, in order to monitor humidity variation in the vicinity of the CPWG sensor.

\section{Materials and Methods}

\subsection{Materials}

Required materials to be used in our oxidation process were obtained. Bleached Kraft wood pulp was used as a raw material. Sodium bromide ( $\mathrm{NaBr})$ and PVOH (Mw 146,000-186,000, 98-99\% hydrolyzed) were obtained from Sigma-Aldrich and used as received. Sodium hypochlorite ( $\mathrm{NaOCl}$ ) was bought locally. The ultrasonic sonotube and ultrasonic generators were supplied by Ultrasonic Power Corporation. The complete sonoreactor was designed, constructed and validated in other studies [28, 29].

\subsection{TOCN-based Gel Synthesis}

A $1.7 \%$ wt gel of TOCN and a composite gel of TOCN/PVOH formed by adding $10 \% \mathrm{PVOH}$ to the first were prepared following the processes depicted in Fig. 3. The TEMPO oxidation was carried out in a sono-reactor (40 litres) on a $500 \mathrm{~g}$ Kraft pulp sample. The use of ultrasounds reduces the quantity of the reagent, and increases the carboxylate rate and the TOCN ratio [30]. The ultrasonic frequency is $170 \mathrm{kHz}$ at $250 \mathrm{~W}$ of ultrasonic power intensity. $\mathrm{pH}$ and temperature were maintained at 10.5 and $25{ }^{\circ} \mathrm{C}$ respectively. TEMPO is a stable nitroxyl radical used to catalyze the oxidation reaction. $\mathrm{NaBr}$ and $\mathrm{NaOCl}$ act as co-oxidants.

TEMPO and $\mathrm{NaBr}$ were dissolved in de-ionized water and added to the fibre suspension. $5 \mathrm{~L}$ of $\mathrm{NaOCl}$ was then added to the solution. The reaction was stopped after 90 minutes. The oxidized fibres were thoroughly washed to eliminate oxidant trace. Thereafter, TOCN were suspended in de-ionized water at a $1.7 \%$ concentration and defibrillated by mechanical treatment. The resulting gel contained $30 \%$ microfibres and 70\% nanofibres with a carboxyl rate of $1600 \mathrm{mmol} / \mathrm{kg}$. At the same time, a PVOH solution was prepared and added $(10 \% \mathrm{wt})$ to the TOCN suspension to form the TOCN/PVOH composite. The mixture was stirred at a low speed to prevent bubble formation. The TOCN and the TOCN/PVOH gels hence fabricated were investigated as humidity sensitive materials. 


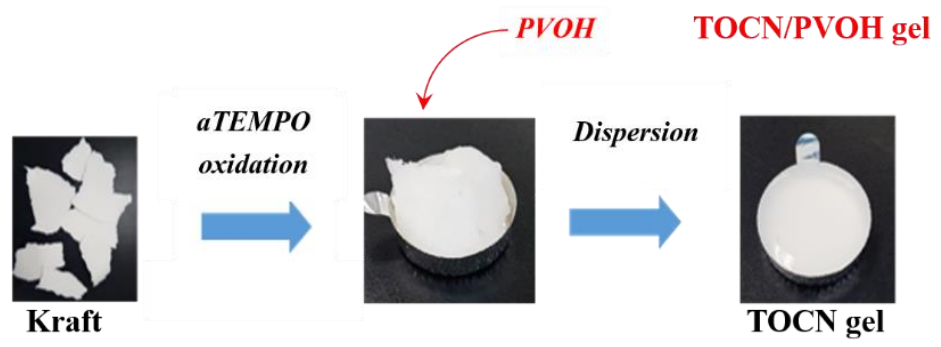

Fig. 3: Synthesis process of TOCN and TOCN/PVOH gels.

\subsection{RH-dependent Dielectric Characterization of TOCN}

To validate their dielectric sensitivity to humidity in test conditions, the dielectric constant of TOCN gels was tested under variable humidity conditions using the characterization method presented in [31]. According to this method, a SIW-based resonator was fabricated (Fig. 4-c). This resonator was $L=4.5$ $\mathrm{cm}$ long and $Y=4.5 \mathrm{~cm}$ wide based on the dimensions presented in Fig. 4-a. Its resonant frequency was measured at $3.923 \mathrm{GHz}$ and used as a reference. The SIW-based resonator was dotted by holes located on the central region, where the EM field was found to be maximum at the resonance (Fig. 4-b). Here, $\alpha=1.3$ $\mathrm{cm}$ so that the perforated area was $\alpha^{2}=1.69 \mathrm{~cm}^{2}$. Following the perturbation theory, the resonant frequency of the SIW-based resonator depends on the dielectric properties of the holes filler [27]. Here, the holes were filled by the TOCN gel to be characterized (Fig. 4-d). The resonator was then exposed to various humidity level ranging from the vacuum to $95 \% \mathrm{RH}$ in 9 steps, with the help of the test bench presented in [24]. The experimental test protocol was the same as [24], including temperature and pressure values. The resonant frequency for each humidity level was measured and compared to the resonant frequency without TOCN. From the measured frequency shift, EM analyses were performed, and a calculation algorithm implementing the characterization method in [31] was applied to rigorously extract the values of the dielectric constant for each humidity level.

The result is presented in Fig. 5, where the variation of the dielectric constant of TOCN gel as a function of humidity is depicted. It appears that the dielectric constant of TOCN film increases with humidity. The water molecules of the humid gas are adsorbed through hydrogen bonding at the surface of the TOCN film, either by carboxyl groups or by hydroxyl groups remaining in cellulose fibres. For low humidity levels, the film structure is quite hermetic due to the strong interaction between fibers [32]. Some water molecules however hardly penetrate the TOCN film in thickness through pores. When humidity increases, the film porosity increases. Water molecules are freed to go deeper and form multiple physical water layers inside the TOCN film, owing to the uneven disposition of cellulose fibers network. Hydrogen bonds and Van der Waals bonds between fibers groups themselves (primary alcohols or carboxyl groups) are then gradually replaced by interactions between water molecule and fibers groups. The TOCN film thickness increases accordingly. In the end, the increase of water molecules on the surface and the swelling of TOCN film due to the presence of water molecules explain the increase of its dielectric constant with humidity.

The rate of TOCN film dielectric constant above $50 \% \mathrm{RH}$ appears higher compared with the rate below. Although this observation is difficult to explain precisely, some hypotheses can be formulated. The first is that the results reflect the dielectric states of TOCN film after the measurement time, that differs from the response time of water adsorption mechanisms. The latter shortens as humidity increases [32]. Here, the results at low humidity levels might correspond to intermediate dielectric states whereas results at high 
humidity levels might correspond to the steady states. The value of $50 \% \mathrm{RH}$ might appear as the threshold point between the relatively low dielectric constant values of intermediate states, and the high values of steady states. The second hypothesis is that from a critical humid gas saturation value, water adsorbed condenses enough to form a thin film at the surface of the TOCN material. Indeed, when humidity increases, other layers add up to the preformed physical adsorbed layers. The electrical capacitance increases and may considerably influence the dielectric state of the TOCN film from a critical value, that is $50 \% \mathrm{RH}$. The third hypothesis is the disruption of the fibre network from a humid gas saturation point. The water molecules interspersed between hydroxyl and carboxyl groups increase with the humid gas saturation. This results in the thickening of the TOCN film, but also in the weakening of fiber cohesion. $50 \% \mathrm{RH}$ may appear as the threshold value from which the loss of cohesion creates an avalanche throughout the TOCN film.

The sensitivity threshold is $20 \% \mathrm{RH}$ in test conditions. The dielectric constant varies from 5.694 at $0 \% \mathrm{RH}$ to 5.781 at $100 \% \mathrm{RH}$. A moderate variation is observed below $50 \% \mathrm{RH}$ and a high sensitivity is observed beyond $50 \% \mathrm{RH}$, where the curve can be approximated by a line of slope $0.012 / \% \mathrm{RH}$. The non-linearity of the curve can be explained by non-linear TOCN interaction mechanisms that arise as humidity increases, especially from $50 \% \mathrm{RH}[24]$.

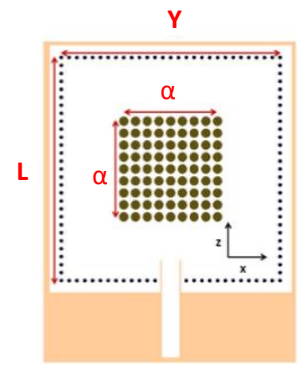

(a)

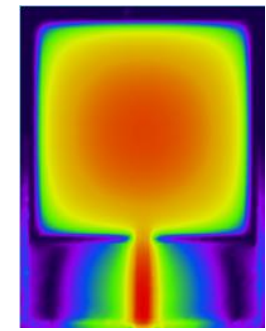

(b)

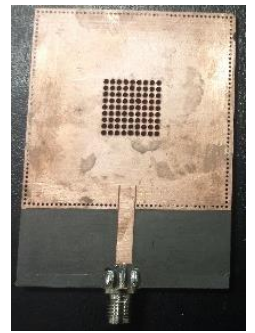

(c)

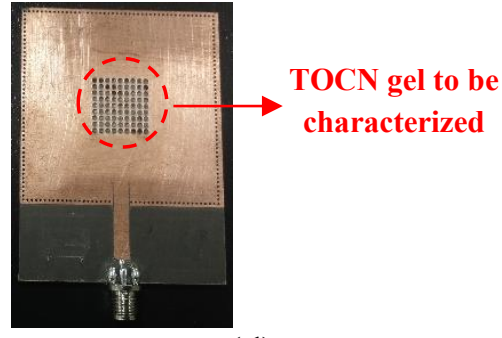

(d)

Fig. 4: SIW resonator used for humidity-dependent dielectric characterization of TOCN films (a) dimensions with $\mathrm{L}=4.5$ $\mathrm{cm}, \mathrm{Y}=4.5 \mathrm{~cm}$ and $\alpha=1.3 \mathrm{~cm}$; (b) EM filed repartition at resonance and fabricated prototype (c) without TOCN; (d) after TOCN insertion.

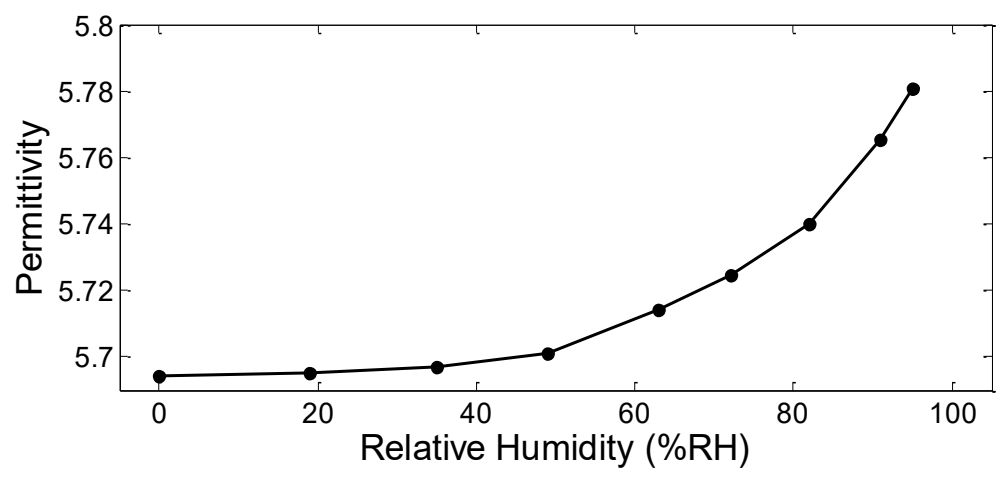

Fig. 5: Dielectric characterization of the TOCN on various RH conditions. 


\subsection{Microwave Design and Sensor Fabrication}

The geometry of the CPWG resonator is detailed in Fig. 6. The characteristic impedance was set to $Z_{0}=50 \Omega$ with the signal width $W=4.23 \mathrm{~mm}$ and the gap width $s=1 \mathrm{~mm}$. The ground width was set to $G=14.85 \mathrm{~mm}$ and the length of the central rectangle to $X=13.60 \mathrm{~mm}$. The half structure resonated for $X \cong \lambda / 2$ [33].

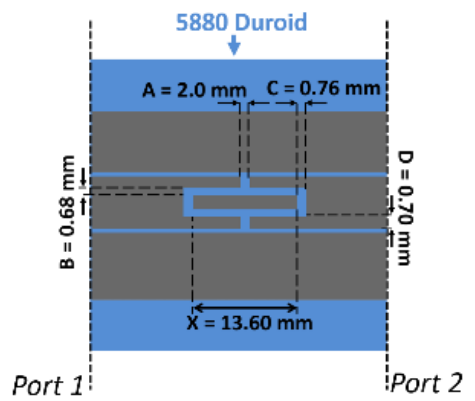

Fig. 6: Geometry and dimensions of the CPWG test device.

EM simulations were achieved with ADS simulation tool from EES suite. The simulated resonant frequency was $f_{r}=8.252 \mathrm{GHz}$. To validate the sensing principle, the EM field distribution was simulated and compared at the resonant frequency and far from the resonance, at $f=5 \mathrm{GHz}$. The results are shown in Fig. 7.

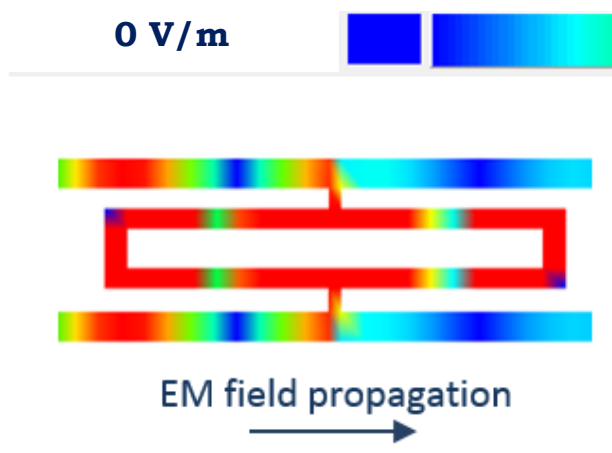

(a)
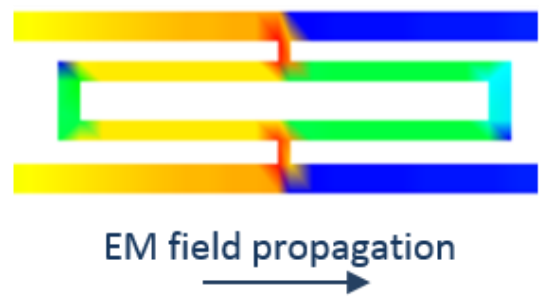

(b)

Fig. 7: EM field repartition of the CPWG test device at two frequency points: (a) at the resonant frequency and (b) at 5 GHz.

The EM distribution analysis shows that far from the resonance, the EM field is reflected to the emitter and that no signal is transmitted (Fig. 7-a). As the frequency comes close to the resonance, the EM energy is gradually flared into the slots around the central rectangle. At the resonance, the EM energy peaks (Fig. 7-b) and the EM signal is transmitted by capacitive coupling. This analysis confirms that the TOCN-based hydrophilic gels are dropped in the region where the EM field is concentrated at the resonance. This is the ideal location to induce significant variations of microwave parameters and achieve humidity sensing with the best performances.

After simulations, the CPWG microwave device was milled on Duroid 5880 substrate from Rogers $\left(\tan \delta=0.0009, \varepsilon_{r}=2.2\right)$ as shown in Fig. 8. This substrate was chosen for its low dielectric losses, its thermal stability up to $150{ }^{\circ} \mathrm{C}$ and its low absorption of water ( $0.02 \%$ after 24 hours) that allows it to be 
considered insensitive in our humidity test conditions [34]. The CPWG microwave device was milled with the LPKF Protomat S103 plotter. Two copies were fabricated: one to host the TOCN gel and another to host the TOCN/PVOH gel. Each circuit was $4.2 \mathrm{~cm}$ long and $3.6 \mathrm{~cm}$ wide. Vias were added to ensure uniform distribution of ground over the top side and the bottom side of the CPWG circuit. Fig. 9 shows good agreement between simulation and measurement for the $S_{11}$ and $S_{21}$ parameters in ambient conditions. Measured insertion losses were $I . L=-0.52 \mathrm{~dB}$.

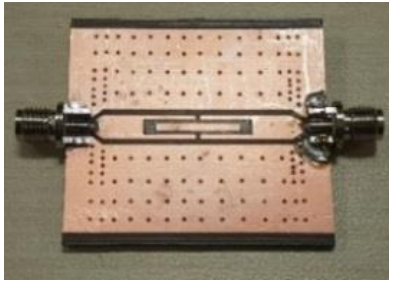

Fig. 8: Picture of the fabricated CPWG test device. The circuit is $4.2 \mathrm{~cm}$ long and $3.6 \mathrm{~cm}$ wide without connetors.

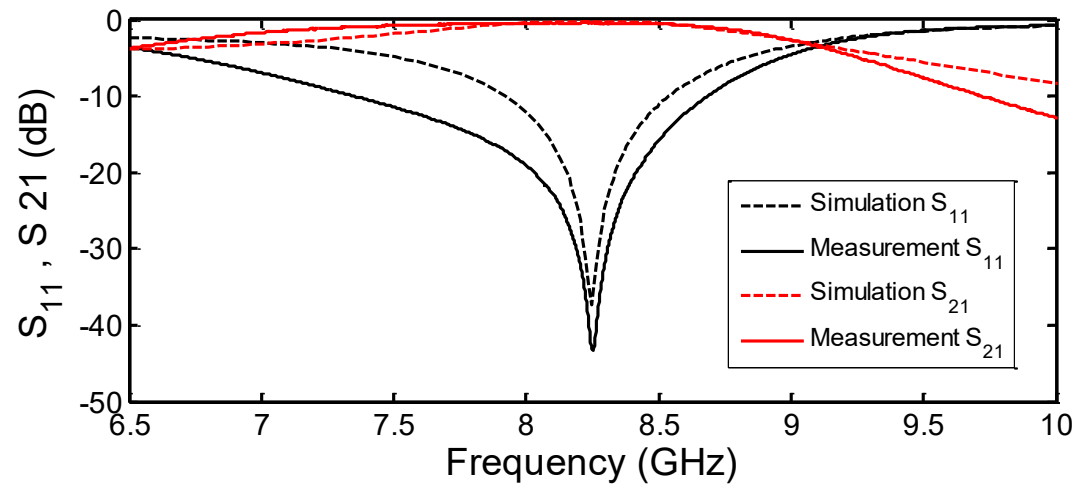

Fig. 9: Simulated and measured S-parameters of the fabricated CPWG test device.

The TOCN and TOCN/PVOH gels were each poured into one separated device. The translucent aspect of the gels makes them almost invisible after they are poured. However, their dielectric influence was revealed by measuring the $S_{11}$ parameter as shown in Fig. 10. Indeed, a resonant frequency and a phase shift occurred after pouring each gel. The resonant frequency shifts with the TOCN and TOCN/PVOH films were $\Delta f_{r 1}=99 \mathrm{MHz}$ and $\Delta f_{r 2}=1.321 \mathrm{GHz}$ respectively. Accordingly, the phase shifts were $\Delta \phi_{1}=97^{\circ}$ and $\Delta \phi_{2}=143^{\circ}$ respectively. These results were coherent as PVOH insertion considerably rises the dielectric constant compared to stand-alone TOCN [35]. Finally, the resonant frequency was $f_{r 1}=8.153 \mathrm{GHz}$ with the TOCN film, and $f_{r 2}=6.931 \mathrm{GHz}$ with the TOCN/PVOH film. Likewise, the $S_{21}$ phase was $\phi_{1}=-17.92^{\circ}$ with the TOCN film and $\phi_{2}=112.3^{\circ}$ with the TOCN/PVOH film. 


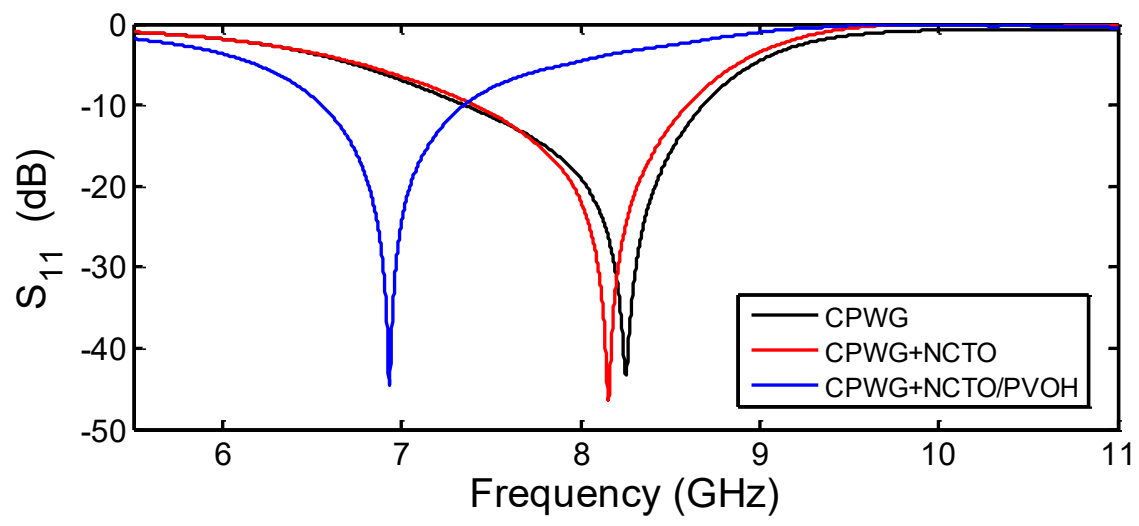

Fig. 10: Comparison of $S_{11}$ parameters of the CPWG test device without sensitive materials, after TOCN pouring and TOCN/PVOH pouring.

\subsection{Humidity Test Set-Up}

The circuit was tested in various humidity conditions with saturated salt solutions that generate fixed humidity levels at constant temperatures and constant volumes [36]. The humidity measurement set-up is illustrated in Fig. 11. The salt solutions were placed inside 4L boxes. The CPWG device supported by cables of the vector network analyzer was placed inside each box through small openings. The following relative humidity values were tested: $21.9 \% \mathrm{RH}$ (ambient conditions), $35.5 \% \mathrm{RH}, 46.8 \% \mathrm{RH}, 54.6 \% \mathrm{RH}$, $68.9 \% \mathrm{RH}, 79.8 \% \mathrm{RH}, 89.3 \% \mathrm{RH}$. S-parameters were saved after 20 minutes for each humidity level. A probe was used to measure the real-time temperature and humidity inside the boxes. The temperature was $23{ }^{\circ} \mathrm{C}$ during all the measurements of humidity response.

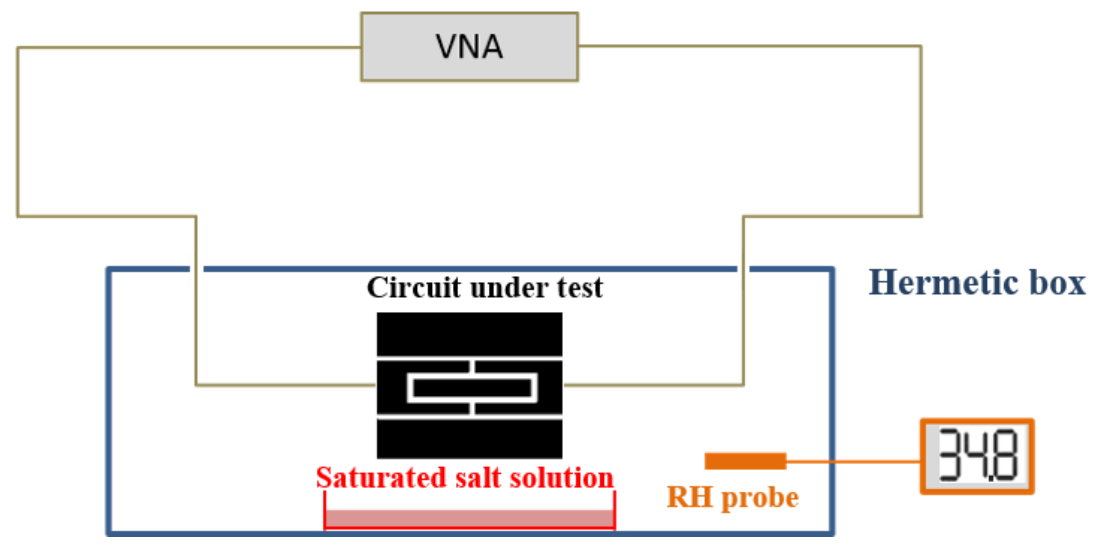

Fig. 11: Illustration of the humidity test set-up.

\section{Frequency and Phase Humidity Responses}




\subsection{Humidity Response}

Measurement results with both resonant frequency and $S_{21}$ phase shift were extracted. For RH variations from $R H_{1}$ to $R H_{2}$ with the corresponding shift of the target parameter from $\delta_{1}$ to $\delta_{2}$, the sensitivity of the sensor $\left(S_{R H}^{\delta}\right)$ is defined by (2). Target parameters here include the resonance frequency and the $S_{21}$ phase.

$$
S_{R H}^{\delta}=\left|\frac{\Delta \delta}{\Delta(R H)}\right|=\left|\frac{\delta_{2}-\delta_{1}}{R H_{2}-R H_{1}}\right|
$$

Fig. 12 shows the variation of the resonant frequency as a function of humidity, with the TOCN film (Fig. 12-a) and the TOCN/PVOH composite film (Fig. 12-b). Measurements were taken three times to ensure the repeatability of the sensing mechanisms.

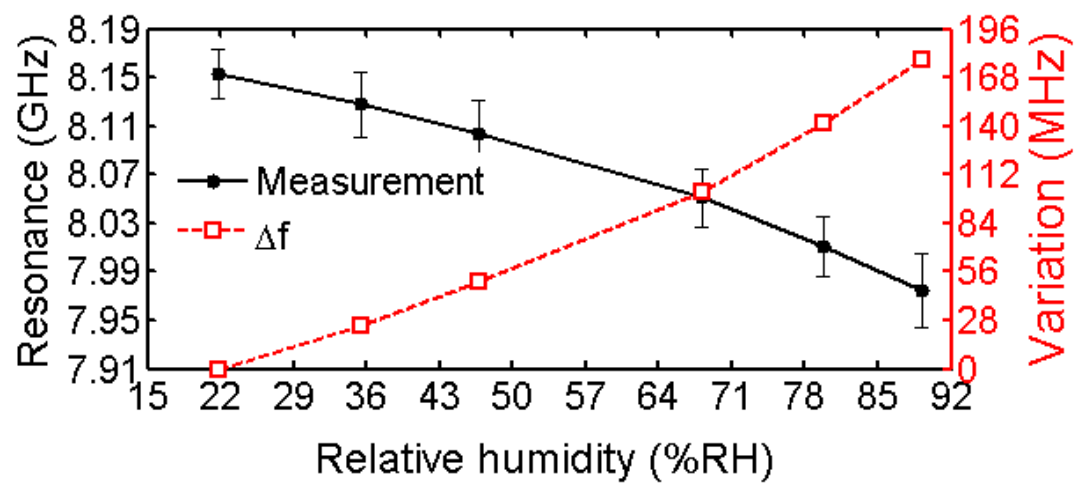

(a)

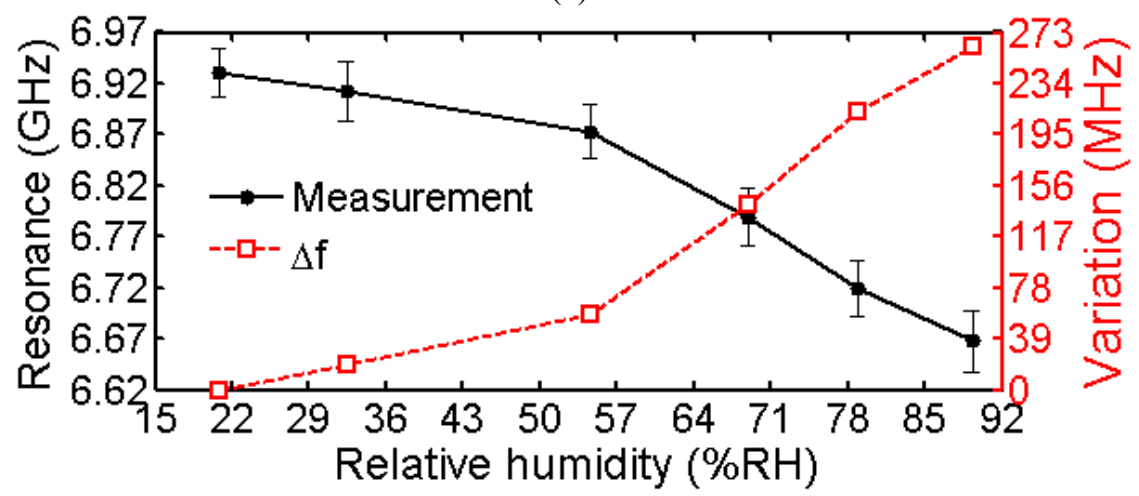

(b)

Fig. 12: Frequency humidity response of CPWG test device (a) with TOCN and (b) with TOCN/PVOH. The temperature was $23{ }^{\circ} \mathrm{C}$ during measurement.

The humidity response with TOCN can be considered linear over all the dynamic range $\left(R^{2}=0.9783\right)$. The overall frequency shift is $178 \mathrm{MHz}$ from $f_{r 1}=8.153 \mathrm{GHz}$ at $21.9 \% \mathrm{RH}$ to $f_{r 1}=7.975 \mathrm{GHz}$ at $89.3 \% \mathrm{RH}$. The sensitivity of TOCN is then $2.677 \mathrm{MHz} / \% \mathrm{RH}$ over the measurement dynamic range. For its part, the humidity response with TOCN/PVOH exhibits a region of low sensitivity below 54.6\% $\% \mathrm{H}$ 
and a region of higher sensitivity beyond this value. The total frequency variation of $263 \mathrm{MHz}$ is distributed between the two regions. The sensitivity is $1.721 \mathrm{MHz} / \% \mathrm{RH}$ below $54.6 \% \mathrm{RH}$ and $6.00 \mathrm{MHz} / \% \mathrm{RH}$ beyond. Fig. 13 shows the variation of the $S_{21}$ phase as a function of humidity with the TOCN film (Fig. 13-a) and the TOCN/PVOH composite film (Fig. 13-b). Once again, measurements were taken three times to ensure the repeatability of the sensing mechanisms.

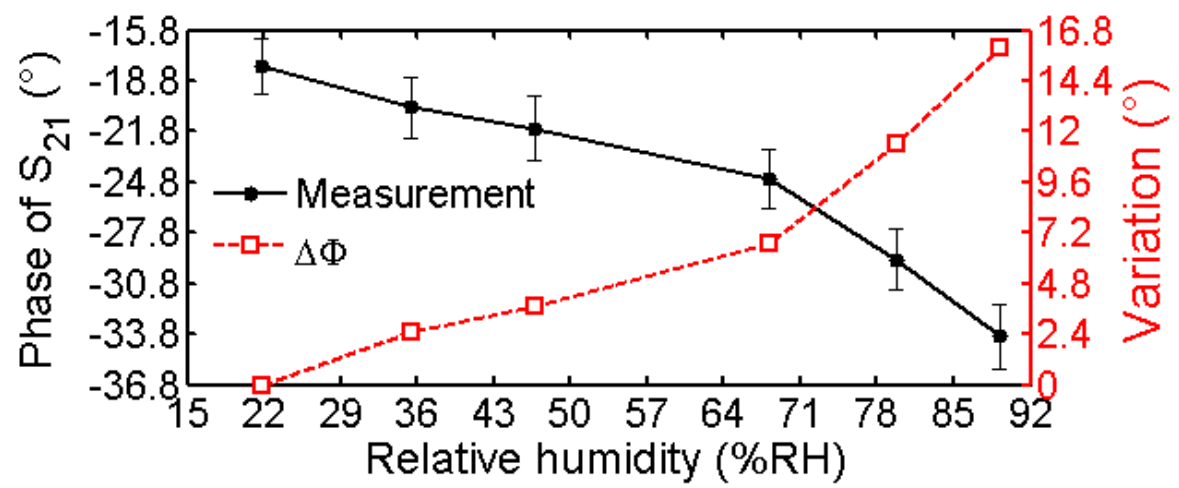

(a)

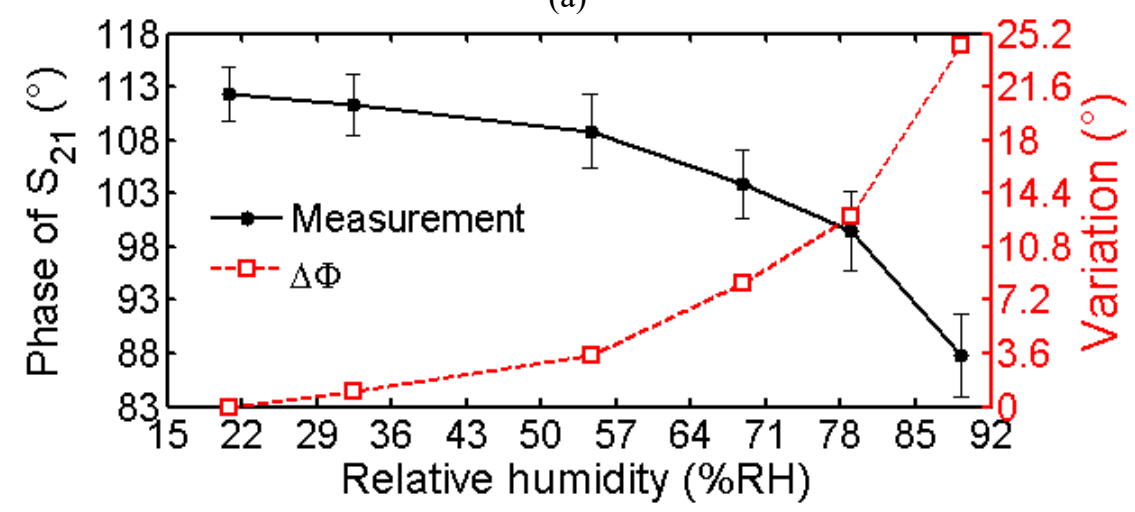

(b)

Fig. 13: $S_{21}$ phase humidity response of CPWG test device (a) with TOCN and (b) with TOCN/PVOH. The temperature was $23{ }^{\circ} \mathrm{C}$ during measurement.

A $S_{21}$ phase shift occurs when a sufficient amount of humidity is absorbed and diffused through the TOCN-based films. The EM signal transmission from one to the other side of the CPWG device is ensured by this condition. The $S_{21}$ phase varies from $\phi_{1}=-17.92^{\circ}$ at $21.9 \% \mathrm{RH}$ to $\phi_{1}=-33.93^{\circ}$ at $89.3 \% \mathrm{RH}$ with the TOCN film, and from $\phi_{2}=112.3^{\circ}$ at $21.9 \% \mathrm{RH}$ to $\phi_{2}=87.87^{\circ}$ at $89.3 \% \mathrm{RH}$ with the $\mathrm{TOCN} / \mathrm{PVOH}$ film. The total phase shift is $16.01^{\circ}$ with the TOCN film and $24.43^{\circ}$ with the TOCN/PVOH film. As shown in Fig. 13, the phase humidity responses exhibit a region of low sensitivity and a region of high sensitivity at a different frontier depending on the sensitive material. The sensitivity is $0.140 \%$ RH below $68.9 \% \mathrm{RH}$ for the TOCN film, and $0.523 \%$ RH beyond as shown in Fig. 13-a. This frontier of $68.9 \% \mathrm{RH}$ for the TOCN film is similar to the frontier of $70 \% \mathrm{RH}$ obtained with TOCN sheets [24]. Likewise, as shown in Fig. 13-b, the sensitivity is $0.105 \%$ RH below $54.6 \% \mathrm{RH}$ and $0.911 \% \% \mathrm{RH}$ beyond this value with the TOCN/PVOH film. Here, the frontier of $54.6 \% \mathrm{RH}$ is explained by the change of humidity sorption mechanisms of $\mathrm{PVOH}$ around $50 \% \mathrm{RH}$. Table I summarizes the results with the TOCN and TOCN/PVOH films on the CPWG-based structure. 
Table I: Summary of humidity-sensing performances of TOCN and TOCN/PVOH gels with the CPWG test structure.

\begin{tabular}{l|cc|cc}
\hline \hline Materials & RH range $(\% \mathrm{RH})$ & $S_{R H}^{f_{r}}(\mathrm{MHz} / \% \mathrm{RH})$ & $\mathrm{RH}$ range $(\% \mathrm{RH})$ & $S_{R H}^{\phi}(\% \% \mathrm{RH})$ \\
\hline \multirow{2}{*}{ TOCN film } & $21.9-89.3$ & 2.677 & $21.9-68.9$ & 0.140 \\
& & & $68.9-89.3$ & 0.523 \\
\hline \multirow{2}{*}{ TOCN/PVOH film } & $21.9-54.6$ & 1.722 & $21.9-54.6$ & 0.105 \\
& $54.6-89.3$ & 6.000 & $54.6-89.3$ & 0.911 \\
\hline
\end{tabular}

\subsection{PVOH Contribution}

The contribution of PVOH to sensing performances is depicted in Fig. 14, which shows relative variation of the resonant frequency of TOCN and TOCN/PVOH $(\Delta)$ as defined in Eq. (3) where $f_{i}$ is the resonant frequency in ambient conditions and $f_{r}$ is the resonant frequency measured at the humidity value.

$$
\Delta=100 \times\left|\frac{f_{r}-f_{i}}{f_{i}}\right|
$$

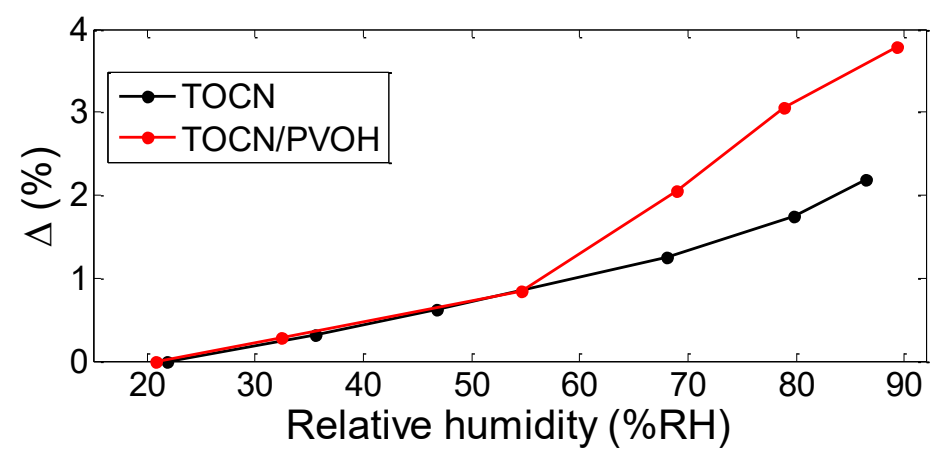

Fig. 14: Relative variation of the humidity response of the CPWG test structure with TOCN and TOCN/PVOH gels.

During TOCN/PVOH film preparation, PVOH chains mix to the TOCN film structure. Two types of materials are thus involved in water adsorption mechanisms: carboxyl groups provided by TEMPO oxidation, hydroxyl groups provided by PVOH chains and the cellulose fibers. PVOH shown low hysteresis characteristics and demonstrated wide frequency range $(0.2-20 \mathrm{GHz})$ in sensing humidity [32, 37]. The sensitivity of the sensor originates from the superposition of TOCN and PVOH sensing mechanisms. The sensor behaves as an electrical transducer which convert the dielectric constant variation of the TOCN film to its resonant frequency variation. The resonant frequency variation as a function of 
humidity reflects the RH-dielectric sensitivity of the TOCN/PVOH film. From Fig. 14, the humidity frequency response for TOCN and TOCN/PVOH films is the same below $54.6 \% \mathrm{RH}$. The PVOH chains are buried deep inside the TOCN film and the interaction with water molecules is insignificant. The frequency response is mainly determined by TOCN surface adsorption mechanisms. Beyond $54.6 \% \mathrm{RH}$, the sensitivity rises notably for TOCN/PVOH films. As explained in section 3.3, the dielectric sensitivity increases from $50 \% \mathrm{RH}$. Moreover, the dielectric sensitivity of PVOH also increase notably from $50 \% \mathrm{RH}$, according to the broadband humidity dependent characterization of PVOH $(12-95 \% \mathrm{RH}$ approximately) $[35,38]$. The combination of the two dielectric mechanisms results in a significant increase of the frequency sensitivity of the TOCN/PVOH film measured from $54.6 \% \mathrm{RH}$.

\subsection{Microwave Performances Analysis}

Derived from the resonance slope introduced by [19], the modified resonance slope $(\mu)$ as defined in Eq. (4) is used here to analyze Q-factor variation over the $\mathrm{RH}$ measurement range. $S_{11 \text { min }}$ is the $S_{11}$ value at the resonant frequency $f_{\text {res }}$, and $S_{11_{-} t h}$ is the threshold value of $S_{11}$ where the performance is acceptable. The corresponding frequency is $f_{t h}$. Here, $S_{11_{-} t h}=-10 \mathrm{~dB}$. The graphic illustration of $(\mu)$ calculation is shown in Fig. 15-b.

$$
\mu=\frac{\delta S_{11}}{\delta f}=\left|\frac{S_{11 \_ \text {min }}-S_{11 \_t h}}{f_{\text {res }}-f_{\text {th }}}\right|
$$

The $\mu$ value measures the influence of losses on the resonance quality as RH increases. Fig. 15 shows the $S_{11}$ parameter curves for various humidity conditions along the dynamic range for TOCN (Fig. 15-a) and TOCN/PVOH films (Fig. 15-b). It is observed that as RH increases, the resonant frequency decreases. The curve shape changes from a pointed shape to a flared shape, showing an increase of losses and therefore a decrease of the Q-factor. Indeed, as shown in Fig. 5, the dielectric constant of TOCN increases with humidity. The capacitive coupling between the CPWG and the central rectangle is then modified. The EM signals encounter higher resistance travelling through the sensitive material and this increases dielectric losses. As a result, Q-factor decreases and, accordingly, so does the modified resonance slope $\mu$. As shown in Fig. $16, \mu_{T O C N}=76.94 \mathrm{~dB} / \mathrm{GHz}$ at $21.9 \% \mathrm{RH}$ and $\mu_{T O C N}=36.18 \mathrm{~dB} / \mathrm{GHz}$ at $86.4 \% \mathrm{RH}$ for TOCN film. The same trend is observed with TOCN $/ \mathrm{PVOH}$ films where $\mu_{T O C N / P V O H}=122.4 \mathrm{~dB} / \mathrm{GHz}$ at $21.9 \% \mathrm{RH}$ and $\mu_{\text {TOCN } P V O H}=25.1 \mathrm{~dB} / \mathrm{GHz}$ at $89.3 \% \mathrm{RH}$. As the TOCN/PVOH combines the sensing mechanisms of TOCN and $\mathrm{PVOH}$, the variation of the capacitive coupling has a stronger impact. The modified resonance slope of TOCN/PVOH decreases faster compared to the TOCN's slope. For high RH values, the sensitive films saturate. The slopes are lower and similar. 


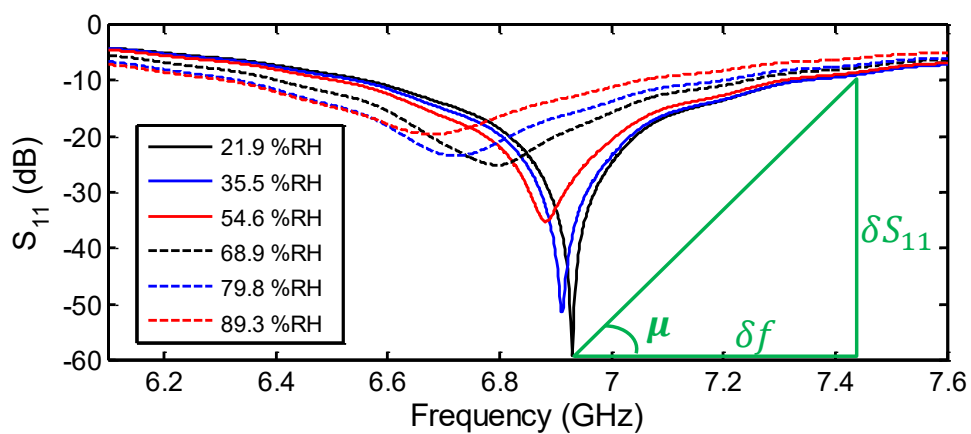

(a)

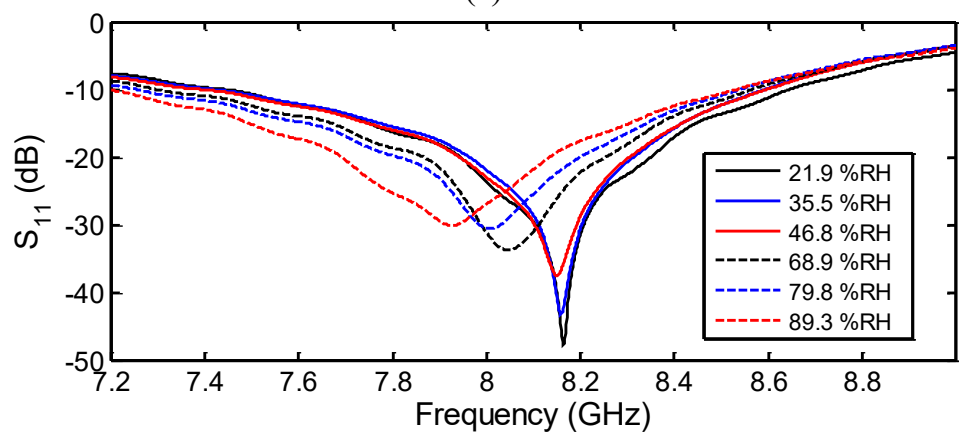

(b)

Fig. 15: $S_{11}$ curves of CPWG test device for various RH levels (a) with TOCN/PVOH and (b) with TOCN.

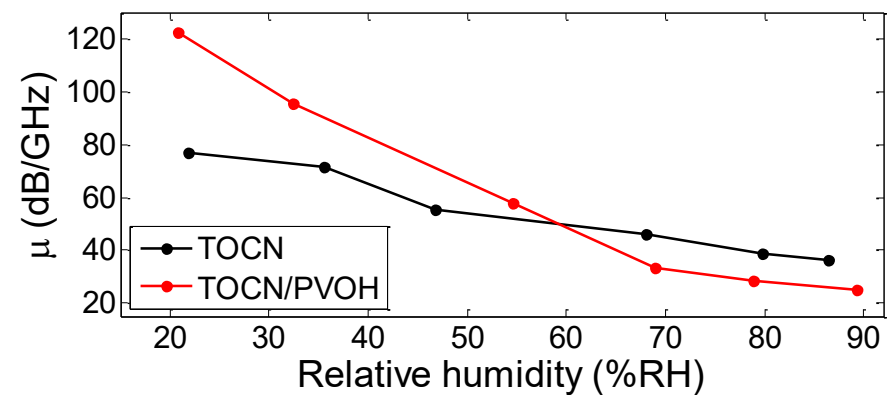

Fig. 16: Modified resonance slope with the CPWG test structure with TOCN and TOCN/PVOH gels.

Concerning the $S_{21}$ phase, the modified phase figure of merit $\left(F_{\phi}\right)$ derived from [39] was measured. Here, the maximum transmission losses instead of average losses were considered as shown in Eq. (5) where $\phi_{21_{\_} f}$ is the final $S_{21}$ phase value (at $89.3 \% \mathrm{RH}$ ), $\phi_{21_{-} i}$ is the initial $S_{21}$ phase value (at $21.9 \% \mathrm{RH}$ ) and $S_{21 \_ \text {min }}$ is the minimum value of $S_{21}$ magnitude along the RH measurement range.

$$
F_{\phi}=\left|\frac{\phi_{21 \_f}-\phi_{21 \_}}{S_{21 \_m i n}}\right|
$$

The $F_{\phi}$ value was measured to determine how the increase of the $S_{21}$ phase induces the increase of transmission losses. Ideally, a phase shift should not increase the transmission losses. As shown in Fig. $17, F_{\phi}$ increases gradually for both TOCN and TOCN/PVOH. For the TOCN film, $S_{21 \_ \text {min }}=-1.46 \mathrm{~dB}$ and $F_{\phi}=10.93 \%$ at $89.3 \%$ RH. For the TOCN/PVOH film, $S_{21 \_m i n}=-2.26 \mathrm{~dB}$ and 
$F_{\phi}=10.80 \% \mathrm{~dB}$ at $89.3 \% \mathrm{RH}$ (Fig. 18). Although $F_{\phi}$ are similar for the two materials, phase variation is higher with TOCN/PVOH since the transmission losses are higher. Indeed, the total phase shift is $16.01^{\circ}$ with the TOCN film and $24.43^{\circ}$ with the TOCN/PVOH film as shown in Fig. 13. However, the overall variation of $S_{21}$ is less than $1 \mathrm{~dB}$ for TOCN films and $1.5 \mathrm{~dB}$ for TOCN/PVOH films. As the total losses are less than $-3 \mathrm{~dB}$, the performance of all these circuits remains interesting for phase-shifting applications.

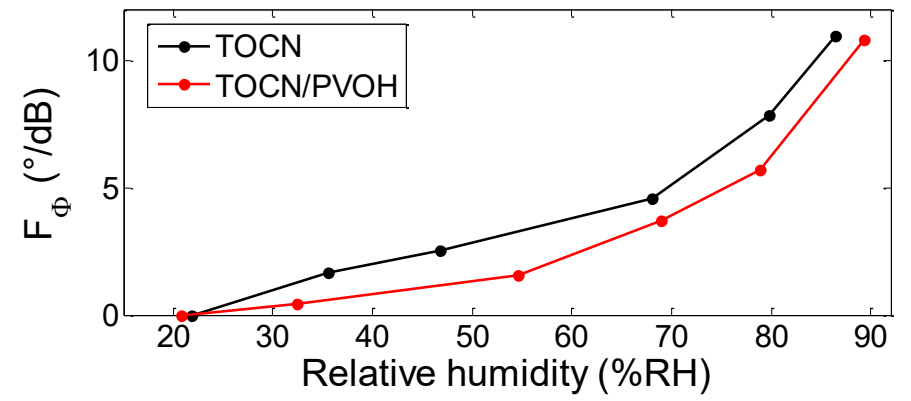

Fig. 17: Modified phase figure of merit with the CPWG test structure with TOCN and TOCN/PVOH gels.

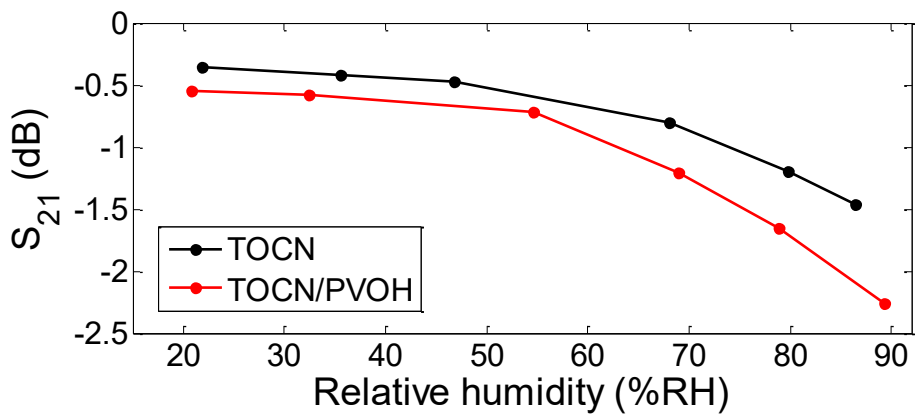

Fig. 18: $S_{21}$ modulus curves of CPWG test device for various RH levels with TOCN and TOCN/PVOH gels.

\section{Comparison and Discussion}

Table II presents the frequency sensitivity obtained with previous microwave structures in transmission line technologies present in the literature. Mainly SIW and CPW technologies have been investigated. The major advantage of SIW is its capacity to achieve humidity sensing without integrating any sensitive material. The highest sensitivity reached is $0.312 \mathrm{MHz} / \% \mathrm{RH}$ in [14]. Much higher sensitivity was reached with $\mathrm{CPW}$ using PVOH, Kapton and TOCN as sensitive materials.

While comparing the results of this research to the literature, some observations can be made. First, the $S_{R H}^{f_{r}}$ value in this article with TOCN is higher than the highest one reached with CPW technology in [19]. The sensing material was PVOH. One explanation may be the high concentration of the EM field in the region where the sensitive materials are deposited. The higher the EM energy in the active region is, the higher the sensitivity is [40]. One advantage of TOCN compared to PVOH is biodegradability.

Secondly, the $S_{R H}^{f_{r}}$ value in this article is similar to the performance obtained in [24] with a TOCN sheet. Furthermore, the humidity response with TOCN-based films is linear in a wider range, from $21.9 \% \mathrm{RH}$ to $89.3 \% \mathrm{RH}$. This appealing performance can be explained by the sensing material properties and the efficiency of the sensing principle. The TOCN films and sheets were $15 \mu \mathrm{m}$ and $36.2 \mu \mathrm{m}$ thick 
respectively. Humidity sorption mechanisms involve adsorption and diffusion through sheets or films. These phenomena take place faster with films due to their thinness. Moreover, the humidity wets the films and makes their texture jelly-like, like sponges, so that higher humidity amounts can be absorbed. When applied to TOCN films, the sensing principle allows for efficiently translating these humidity interactions to microwave parameter variations despite the restricted active area. In the end, the results with TOCN films and TOCN sheets are comparable.

Finally, the $S_{R H}^{f_{r}}$ value of $6.00 \mathrm{MHz} / \% \mathrm{RH}$ reached in this article with TOCN/PVOH films is by far the best sensitivity measured with a microwave structure and transmission line technologies. As thoroughly explained earlier, the sensing scheme and the combination of the sensing mechanisms of TOCN and $\mathrm{PVOH}$ considerably raises the humidity sensitivity above the $50 \% \mathrm{RH}$ humidity level.

Table III presents the phase sensitivity obtained with previous microwave structures in transmission line technologies present in the literature. The $S_{R H}^{\phi}$ obtained in this research for TOCN films is lower than the result obtained with the TOCN sheets in [24]. This result may be explained by the spatial coverage of the dielectric region in the two configurations. While propagating through CPWG-based devices, the group delay of the EM wave depends on the structural parameters of the surrounding dielectric regions. Here, the thickness and the length of the dielectric region associated to TOCN sheets are bigger than the ones associated to TOCN films. Changes in dielectric properties on the sheet have a higher impact than small gels inserted within slots. However, the high sensitivity of $\mathrm{PVOH}$ causes the phase sensitivity of TOCN/PVOH films to be the most sensitive. 
Table II: Summary of humidity frequency sensitivity of TOCN and TOCN/PVOH gels with the CPWG test structure, and comparison with literature.

\begin{tabular}{|c|c|c|c|c|c|c|}
\hline Microwave technologies & Structures & Sensitive materials & $\begin{array}{r}\text { Sensitivity } \\
\text { (MHz/\%RH) }\end{array}$ & $\% \mathrm{RH}$ range & Year & Ref. \\
\hline Coplanar waveguide (CPW) & Steeped impedance resonator & PVOH film & 2.380 & $50.0-90.0$ & 2013 & [19] \\
\hline Coplanar waveguide (CPW) & Steeped impedance resonator & Kapton sheet & 0.630 & $50.0-90.0$ & 2013 & [19] \\
\hline Substrate integrated waveguide (SIW) & Resonator & - & 0.101 & $0.00-80.0$ & 2015 & [12] \\
\hline Half-mode SIW (HMSIW) & Resonator & Graphene Oxide & 0.770 & $11.3-84.3$ & 2018 & [16] \\
\hline Quarter-mode SIW (QMSIW) & Resonator & - & 0.037 & $0.00-80.0$ & 2017 & [15] \\
\hline Ridged QMSIW (RQMSIW) & Resonator & - & 0.031 & $0.00-70.0$ & 2017 & [15] \\
\hline Substrate integrated waveguide (SIW) & Resonator with sensing slots & Black phosphorus & 0.198 & $11.3-97.3$ & 2017 & [4] \\
\hline Air-filled substrate integrated cavity & Resonator & - & 1.210 & $20.0-85.0$ & 2017 & [41] \\
\hline Substrate integrated waveguide (SIW) & $\mathrm{N}$ coupled resonators & - & 0.173 & $6.50-93.0$ & 2016 & [13] \\
\hline Evanescent mode HMSIW & Resonator & - & 0.312 & $11.3-84.3$ & 2017 & [14] \\
\hline Coplanar waveguide (CPW) & Resonator with sensing slots & TOCN sheet & 2.826 & $55.0-100$ & 2017 & [24] \\
\hline Grounded CPW (CPWG) & Resonator with sensing slots & TOCN film & 2.677 & $21.9-89.3$ & 2019 & This \\
\hline Grounded CPW (CPWG) & Resonator with sensing slots & TOCN/PVOH film & 6.000 & $54.6-89.3$ & 2019 & work \\
\hline
\end{tabular}

Table III: Summary of humidity phase sensitivity of TOCN and TOCN/PVOH gels with the CPWG test structure, and comparison with literature.

\begin{tabular}{lllcrcr}
\hline \multicolumn{1}{c}{ Microwave technologies } & \multicolumn{1}{c}{ Structures } & Sensitive materials & $\begin{array}{c}\text { Sensitivity } \\
(\% \% \text { RH })\end{array}$ & \%RH range & Year & Ref. \\
\hline Coplanar waveguide (CPW) & Resonator with sensing slots & TOCN sheet & 0.702 & $70.0-100$ & 2017 & {$[24]$} \\
\hline Grounded CPW (CPWG) & Resonator with sensing slots & TOCN film & 0.523 & $68.1-89.3$ & 2019 & This \\
Grounded CPW (CPWG) & Resonator with sensing slots & TOCN/PVOH film & 0.911 & $54.6-89.3$ & 2019 & work \\
\hline
\end{tabular}




\section{Conclusion}

This paper investigated the humidity-dependent dielectric sensitivity of TEMPO oxidized nanocellulose (TOCN) films in grounded coplanar waveguide technology (CPWG). The preparation of TOCN and TOCN/PVOH hydrophilic sensitive films was presented. An innovative approach to functionalizing slotted microwave CPWG-based resonator was proposed and validated through the electromagnetic (EM) energy analysis at the resonance. The CPWG-based resonator was fabricated. TOCN and TOCN/PVOH gels were dropped in the region where the EM field peaks at the resonance. Humidity tests were then conducted both in reflection and in transmission. On the one hand, the humidity frequency response was linear with TOCN films, over the 21.9-89.3\%RH measurement range. The sensitivity was $2.68 \mathrm{MHz} / \% \mathrm{RH}$. With TOCN/PVOH films, the best sensitivity was $6.00 \mathrm{MHz} / \% \mathrm{RH}$ above 54.6\%RH. On the other hand, the phase sensitivity was $0.523 \% \mathrm{RH}$ above $68 \% \mathrm{RH}$ with TOCN films, and $0.911 \% \mathrm{RH}$ above 54.6\%RH with TOCN/PVOH films. The transmission losses were limited to $-1.46 \mathrm{~dB}$ and $-2.26 \mathrm{~dB}$ respectively.

\section{Acknowledgments}

This research was undertaken with the support of the Canada Research Chairs program and the National Science and Engineering Research Council of Canada. 


\section{$\underline{\text { References }}$}

1. Lee, C.-Y. and G.-B. Lee, Humidity sensors: a review. Sensor Letters, 2005. 3(1-2): p. 1-15.

2. Farahani, H., R. Wagiran, and M.N. Hamidon, Humidity Sensors Principle, Mechanism, and Fabrication Technologies: A Comprehensive Review. Sensors, 2014. 14(5): p. 7881-7939.

3. Sikarwar, S. and B. Yadav, Opto-electronic humidity sensor: A review. Sensors and Actuators A: Physical, 2015. 233: p. 54-70.

4. Chen, C.M., J. Xu, and Y. Yao, SIW resonator humidity sensor based on layered black phosphorus. Electronics Letters, 2017. 53(4): p. 249-251.

5. Amin, E.M., et al., Development of a low cost printable chipless RFID humidity sensor. IEEE Sensors Journal, 2014. 14(1): p. 140-149.

6. $\quad$ Chen, Z. and C. Lu, Humidity sensors: a review of materials and mechanisms. Sensor letters, 2005. 3(4): p. 274-295.

7. Blank, T., L. Eksperiandova, and K. Belikov, Recent trends of ceramic humidity sensors development: A review. Sensors and Actuators B: Chemical, 2016. 228: p. 416-442.

8. $\quad$ Karmakar, N.C., E.M. Amin, and J.K. Saha, Chipless RFID Sensors. 2016: John Wiley \& Sons.

9. $\quad$ Vena, A., et al., Toward a Reliable Chipless RFID Humidity Sensor Tag Based on Silicon Nanowires. IEEE Transactions on Microwave Theory and Techniques, 2016. 64(9): p. 2977-2985.

10. Salmerón, J.F., et al., Printed single-chip UHF passive radio frequency identification tags with sensing capability. Sensors and Actuators A: Physical, 2014. 220: p. 281-289.

11. Simons, R.N., Coplanar waveguide circuits, components, and systems. Vol. 165. 2004: John Wiley \& Sons.

12. El Matbouly, H., N. Boubekeur, and F. Domingue, Passive microwave substrate integrated cavity resonator for humidity sensing. IEEE Transactions On Microwave Theory And Techniques, 2015. 63(12): p. 4150-4156.

13. Ndoye, M., et al., Passive Monolithic Microwave Multisensor based on N coupled Substrate Integrated Resonators for Environmental Detection, in EuMW. 2016.

14. Chen, C.-M. and J. Xu, A miniaturized evanescent mode HMSIW humidity sensor. International Journal of Microwave and Wireless Technologies, 2018. 10(1): p. 87-91.

15. Jones, T.R., M.H. Zarifi, and M. Daneshmand, Miniaturized Quarter-Mode Substrate Integrated Cavity Resonators for Humidity Sensing. IEEE Microwave and Wireless Components Letters, 2017. 27(7): p. 612-614.

16. Chen, C.-M., J. Xu, and Y. Yao, Fabrication of miniaturized CSRR-loaded HMSIW humidity sensors with high sensitivity and ultra-low humidity hysteresis. Sensors and Actuators B: Chemical, 2018. 256: p. 1100-1106.

17. Gupta, K.C., Microstrip lines and slotlines. 2nd ed. ed. 1996, Boston: Artech House. xvi, 535 p.

18. Hettak, K., et al., A class of novel uniplanar series resonators and their implementation in original applications. Microwave Theory and Techniques, IEEE Transactions on, 1998. 46(9): p. 1270-1276.

19. Amin, E.M., N.C. Karmakar, and B. Winther-Jensen, Polyvinyl-alcohol (pva)-based rf humidity sensor in microwave frequency. Progress In Electromagnetics Research B, 2013. 54: p. 149-166.

20. Ummartyotin, S. and H. Manuspiya, A critical review on cellulose: From fundamental to an approach on sensor technology. Renewable and Sustainable Energy Reviews, 2015. 41: p. 402-412.

21. Molina-Lopez, F., D. Briand, and N.F. de Rooij, All additive inkjet printed humidity sensors on plastic substrate. Sensors and Actuators B: Chemical, 2012. 166-167(0): p. 212-222.

22. Mahadeva, S.K., S. Yun, and J. Kim, Flexible humidity and temperature sensor based on cellulosepolypyrrole nanocomposite. Sensors and Actuators A: Physical, 2011. 165(2): p. 194-199.

23. Kotresh, S., et al., Humidity sensing performance of spin coated polyaniline-carboxymethyl cellulose composite at room temperature. Cellulose, 2016. 23(5): p. 3177-3186.

24. Ayissi Eyebe, G., et al., Environmentally-friendly cellulose nanofibre sheets for humidity sensing in microwave frequencies. Sensors and Actuators B: Chemical, 2017. 245: p. 484-492. 
25. Saito, T. and A. Isogai, TEMPO-mediated oxidation of native cellulose. The effect of oxidation conditions on chemical and crystal structures of the water-insoluble fractions. Biomacromolecules, 2004. 5(5): p. 1983-1989.

26. Dib, N.I., Theoretical characterization of coplanar waveguide transmission lines and discontinuities. 1992.

27. Pozar, D.M., Microwave engineering. 4th ed. 2012, Hoboken, N.J.: John Wiley \& Sons. xvii, 732 p.

28. Loranger, E., et al., Comparative study of sonochemical effects in an ultrasonic bath and in a large-scale flow-through sonoreactor. Chemical Engineering Journal, 2011. 178: p. 359-365.

29. Paquin, M., et al., The Use of Weissler Method for Scale-Up a Kraft Pulp Oxidation by TEMPO-Mediated System from a Batch Mode to a Continuous Flow-Through Sonoreactor. Ultrasonics Sonochemistry, 2013. 20(1): p. 103-108.

30. Mishra, S.P., et al., The use of sodium chlorite in post-oxidation of TEMPO-oxidized pulp: Effect on pulp characteristics and nanocellulose yield. Journal of wood chemistry and technology, 2012. 32(2): p. 137148.

31. Sama, N., et al. Partially-open SIW resonator for microwave characterization of particulate dielectrics: Effect of interaction with gases. in Electromagnetics: Applications and Student Innovation Competition (iWEM), 2016 IEEE International Workshop on. 2016. IEEE.

32. Sengwa, R.J. and K. Kaur, Dielectric dispersion studies of poly (vinyl alcohol) in aqueous solutions. Polymer International, 2000. 49(11): p. 1314-1320.

33. Dib, N. and P. Katehi, Modeling of shielded CPW discontinuities using the space domain integral equation method (SDIE). Journal of electromagnetic waves and applications, 1991. 5(4-5): p. 503-523.

34. Corporation, R. https://www.rogerscorp.com/.

35. Lu, D., et al. Humidity dependent permittivity characterization of polyvinyl-alcohol film and its application in relative humidity $R F$ sensor. in Microwave Conference (EuMC), 2014 44th European. 2014.

36. Greenspan, L., Humidity fixed points of binary saturated aqueous solutions. Journal of research of the national bureau of standards, 1977. 81(1): p. 89-96.

37. Sakai, Y., Y. Sadaoka, and M. Matsuguchi, Humidity sensors based on polymer thin films. Sensors and Actuators B: Chemical, 1996. 35(1): p. 85-90.

38. Lu, D., et al., Broadband Permittivity Characterization of Polyvinyl-Alcohol Film for Humidity Sensing Applications. IEEE Transactions on Microwave Theory and Techniques, 2016. 64(10): p. 3255-3263.

39. Vendik, O.G., I.B. Vendik, and M.A. Nikol'ski. Comparison of MMIC phase shifters using figure of merit as the main characteristic. in Microwaves, Radar and Wireless Communications, 2004. MIKON-2004. 15th International Conference on. 2004.

40. Ndoye, M., et al., Sensitivity evaluation of dielectric perturbed substrate integrated resonators for hydrogen detection. Sensors and Actuators A: Physical, 2016. 251: p. 198-206.

41. Ndoye, M., et al., Air-filled substrate integrated cavity resonator for humidity sensing. Sensors and Actuators B: Chemical, 2017. 252: p. 951-955. 